
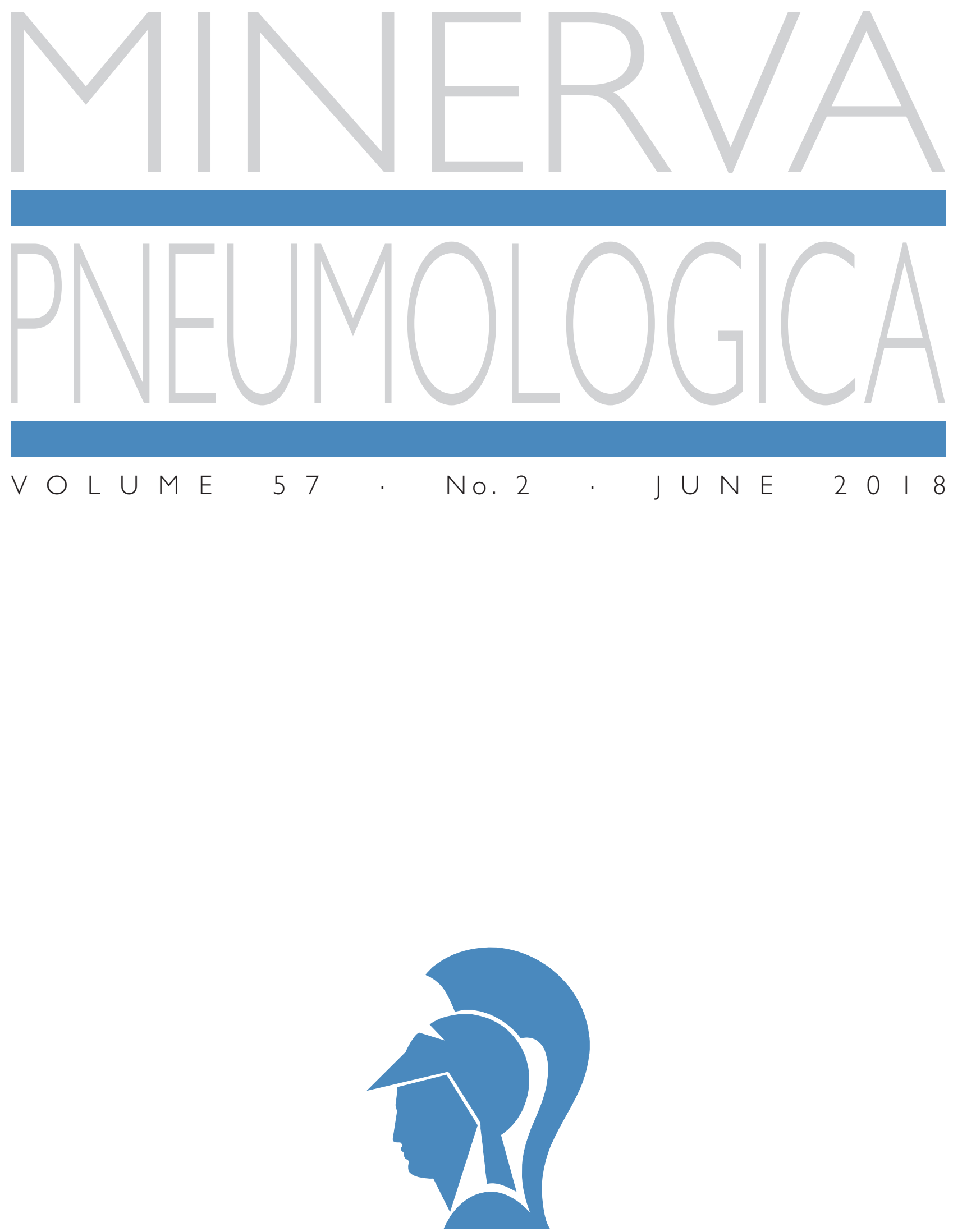

$E D|Z| O N \mid$. $M \mid N E R V A$. MED | C A 


\title{
Exhaled breath condensate in chronic obstructive pulmonary disease: methodological challenges and clinical application
}

\author{
Zsófia LÁZÁR ${ }^{1}$, Ildikó HORVÁTH ${ }^{2}$, Jørgen VESTBO ${ }^{3}$, András BIKOV 1,4*
}

\begin{abstract}
${ }^{1}$ Department of Pulmonology, Semmelweis University, Budapest, Hungary; ${ }^{2}$ National Korányi Institute of Pulmonology, Budapest, Hungary; ${ }^{3}$ Division of Infection, Immunity and Respiratory Medicine, University of Manchester, Manchester, UK; ${ }^{4}$ NIHR Manchester Clinical Research Facility, Manchester University NHS Foundation Trust, Manchester, UK
\end{abstract}

*Corresponding author: András Bikov, NIHR Manchester Clinical Research Facility, Manchester University NHS Foundation Trust, Wythenshawe Hospital, Southmoor Road, M23 9LT, Manchester, UK. E-mail: andras.bikov@mft.nhs.uk

\section{A B S T R A C T}

Collection of exhaled breath condensate (EBC) is a non-invasive method to sample the airway lining fluid. The composition of EBC may reflect physiological and pathophysiological processes within the lower airways, which could otherwise be investigated only with more invasive techniques. Hence, analysis of the condensate fluid seems feasible in chronic obstructive pulmonary disease (COPD) to monitor disease processes and facilitate personalized therapy. In the past two decades, a multitude of molecules has been assessed in EBC samples from patients with COPD, characterizing inflammation, oxidative and nitrative stress in this disorder. Recently, multimarker profiling with sensitive metabolomic or proteomic approaches, optimized for the EBC matrix, has also been applied, which could overcome the pitfalls of single marker detection using commercial assay systems. In this review, we describe the theoretical background of EBC formation, systematically discuss technical and methodological difficulties of sample collection and analysis and summarize data on EBC biomarkers in COPD. Finally, based on previous findings and our experience, we propose potential future directions for the EBC research community, which could pave the way for introducing EBC analysis in clinical practice.

(Cite this article as: Lázár Z, Horváth I, Vestbo J, Bikov A. Exhaled breath condensate in chronic obstructive pulmonary disease: methodological challenges and clinical application. Minerva Pneumol 2018;57:42-56. DOI: 10.23736/S00264954.18.01816-3)

KEY WORDS: Breath tests - Diagnostic techniques, respiratory system - Inflammation mediators - Pulmonary disease, chronic obstructive.

C Thronic obstructive pulmonary disease (COPD) is associated with airway inflammation, which leads to small airways disease and parenchymal destruction. Assessing airway inflammation potentially contributes to disease monitoring and facilitate personalized therapy. Inflammatory markers can be measured in airway samples including induced sputum and exhaled breath, which are collected semi- or non-invasively, therefore imposing minimal risk and discomfort to patients. Exhaled breath condensate (EBC) can easily be obtained during tidal breathing even in patients with severe airflow limitation. In the past two decades numerous disease markers have been identified in EBC of patients with COPD; ${ }^{1-5}$ however, finding the role for this sampling technique in the clinical practice is still underway.

As a reflection of the interest from the research and clinical communities, an international task force report on EBC was endorsed by the European Respiratory Society and the American Thoracic Society in 2005, and a technical standard 
document on the topic was published in 2017.4,5 These and other publications underline the methodological difficulties of this approach, such as sample analysis and data interpretation. ${ }^{2,} 3$ The methodological and clinical details on EBC analysis in various pulmonary and extrapulmonary diseases are detailed in these documents.

In the current review, we focus on exhaled breath condensate findings from studies on patients with COPD. We introduce the sampling technique, systematically assess technical issues (sample collection, confounding factors, detection methods, marker variability), identify markers detected in COPD and summarise recent knowledge with the aim to highlight current and future application of EBC biomarkers in COPD.

\section{Origin and formation of EBC constituents}

\section{Source of EBC components}

During sample collection, subjects are breathing normally inhaling through their nose or mouth and their exhaled breath is cooled down on a cold surface to generate the condensate fluid. Air is fully saturated with water vapour in the airways, therefore the collected condensate fluid is a highly diluted solution, $>99 \%$ of its composition is $\mathrm{H}_{2} \mathrm{O}$. Other compounds are either volatile molecules or non-volatile substances, which are added to the breath in the lower and upper airways, pharynx, oral cavity and salivary glands (Figure 1). However, the detection of water soluble volatiles in $\mathrm{EBC}$ in their non-volatile form may be misleading due to their variable distribution between the condensate fluid, saliva and exhaled air.

Some compounds originate predominantly from the lower airways, as it was shown for adenosine, adenosine triphosphate (ATP), nitrate, thromboxane $\mathrm{B}_{2}\left(\mathrm{TXB}_{2}\right)$ and $\mathrm{pH}$ measurements in patients with tracheostomy or endotracheal tube. Other molecules, such as ammonia or nitrate demonstrated upper airway origin. ${ }^{5-7}$

Formation of respiratory droplets from the airway lining fluid in the lower airways

The main advantage of the EBC technique compared to other options (e.g. bronchoalveolar la- vage, induced sputum) is that it is completely non-invasive and it samples (at least partly) the airway lining fluid (ALF), thereby reflecting physiological and pathological processes in the lower airways. Non-volatile substances of EBC can be released as respiratory droplets (aerosols or aerosolized particles) from the ALF. The formation and origin of these respiratory droplets within the airways are still under debate.

A likely model is the so-called bronchiole fluid film burst concept, which puts forward that exhaled particles are mainly formed in the peripheral airways. At the end of expiration, bronchioles are contracted and blocked, but they reopen during inhalation, which generates a transient rupture in ALF to release aerosols. These droplets are transported to the alveoli by the end of inspiration and then exhaled. The number of exhaled aerosol particles is increased by rapid inhalation, deep exhalation and elevated minute ventilation, and it shows high inter-individual variability. 3,8

Contamination of $\mathrm{EBC}$ from the oral cavity and upper airways

Constituents of EBC are only partly derived from the lower airways as the sample can be contaminated from other organs including the pharynx, oral cavities, salivary glands and nasal airways. Therefore, contamination of some EBC markers measured in COPD studies was tested.

Effros et al. implicated that EBC acidification

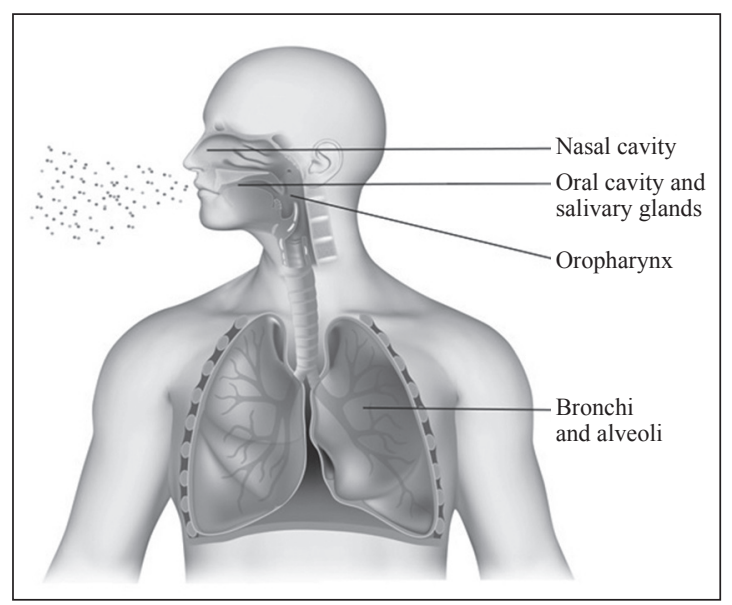

Figure 1.- Origin of exhaled components in EBC. 
in COPD may reflect salivary rather than airway acidification. ${ }^{9}$ Supporting this, mouthwash with antibacterial chlorhexidine-digluconate prevented a reduction in $\mathrm{EBC} \mathrm{pH}$ induced by drinking sugary drink. ${ }^{10}$

Salivary source for leukotriene $\mathrm{B}_{4}\left(\mathrm{LTB}_{4}\right)$ in EBC was implicated as the mediator could be detected only in 4 samples out of 102 that were contaminated with saliva as measured with amylase activity. ${ }^{11}$

A percentage of 63-71 of proteins found in low quantity in EBC can also be detected in higher amounts in saliva as shown by proteomic analysis of samples collected from healthy volunteers. Hence, the authors implicated that EBC proteins are likely to have salivary rather than lower airway origin. ${ }^{12}$ In contrary, another study also using proteomic approach identified 153 proteins as reliable "core" proteins in EBC, and only eight of them are expressed specifically in salivary glands. ${ }^{13}$

EBC nitrite concentration was lowered by antibacterial washing of the oropharynx, which suggest that formation of nitrite from nitrate takes place in the oral cavity and salivary glands, and it involves bacterial activity. ${ }^{7}$ Hence, rinsing the oral cavity with an antibacterial solution before EBC collection should be advised if nitric oxides are wished to be measured.

Metabolomic profile of saliva was tested using nuclear magnetic resonance (NMR) spectroscopy, and it could be significantly distinguished from the profile of EBC samples in patients with COPD. ${ }^{14}$

Inflammation in the nose and nasal sinuses can influence EBC composition if the sample is collected via inhalation through the nose, as respiratory droplets from the nasal airway lining fluid can be released and exhaled. It was shown that concentrations of nitrite, nitrate, $\mathrm{TXB}_{2}$, ammonia were not different in EBC samples collected with nasal and oral inhalation routes in healthy controls, but adenosine level was increased in EBC collected during nasal inhalation in patients with allergic rhinitis. 5,15

\section{Contamination of EBC from external sources}

The presence of substances in EBC is not linked to an airway biological process in some cases as substances in the ambient air can contaminate the condensate fluid, food ingestion can modify airways production of molecules, and the sample can also be contaminated by the collection devices and during processing.

A recent study has shown that EBC hydrogen peroxide $\left(\mathrm{H}_{2} \mathrm{O}_{2}\right)$ levels are significantly affected by environmental $\mathrm{H}_{2} \mathrm{O}_{2} \cdot{ }^{16}$ When proteins were identified in EBC with gel electrophoresis, skin keratins were found to be the most abundant components, most probably a contaminant of ambient air inhaled during EBC collection. ${ }^{17}$ Authors could decrease the quantity of these contaminants using compressed air for inhalation during sample collection.

Utmost attention should be paid to sample collection and processing if researchers want to measure nitric oxides in EBC. High amounts of food rich in nitrate modify the concentration of nitrate and to a higher extent also nitrite levels in EBC. ${ }^{7}$ Furthermore, it is known that nitrate is a common laboratory contaminant, and inappropriate cleaning of the collection device or the contact of sampling equipment with skin or gloves during EBC collection and analysis can cause a significant and false increase in the concentration of nitric oxide metabolites. ${ }^{18}$ Even storage of the collection device on room air for a longer period before EBC collection can cause artificially elevated nitrite concentration in collected samples. ${ }^{19}$ In addition, sample containers might also emit nitrate/nitrite into the condensate fluid, therefore sample analysis should be performed as soon as possible after collection. ${ }^{5}$

The effect of disinfecting reusable collecting devices on EBC metabolomic profile using nuclear magnetic resonance (NMR) spectroscopy was investigated. The authors found that the disinfectant protocol causes no artificial alteration in the NMR signals, and it had no negative effect on the discriminating potential of this technique for COPD. ${ }^{20}$ However, another group reported significant effects of the cleansing protocol on the EBC profile and they therefore suggested the use of non-reusable collection parts for NMR analysis. ${ }^{21}$

A study analysing EBC of normal controls with liquid chromatography and mass spectrometry as a proteomic approach found that ten pro- 
teins out of 153 detected in EBC were contaminants of samples processing. ${ }^{13}$

Adenosine triphosphate (ATP) can be found in all organic material (live or dead), and on laboratory surfaces and human skin. Therefore, EBC for purine analysis should be collected in non-reusable or sterile equipment, and samples should be processed with caution to avoid external contamination. ATP can be found in high concentration in saliva, therefore salivary contamination in EBC should be tested when measuring purine mediators.

\section{Clinical confounding factors relevant for $\mathrm{EBC}$ studies in COPD}

Current cigarette smoking, even without concomitant COPD, can influence inflammatory mediator concentrations in $\mathrm{EBC}$ and confound data interpretation. However, the effect of smoking on EBC biomarkers is not consistent. Elevated concentration of $\mathrm{H}_{2} \mathrm{O}_{2}, 8$-isoprostane and nitrotyrosine were reported in smokers, 5,22 but cigarette smoke-induced increase in EBC nitrotyrosine was not confirmed by another study. ${ }^{5}$ Smoking two cigarettes induced a transient increase in EBC nitrate concentration ${ }^{5}$ in healthy volunteers. There was a direct correlation between smoking and surfactant protein D concentration, while an indirect relationship was observed with club cell protein level. ${ }^{23}$ In contrast, acute smoking did not affect EBC IL-1 $\beta$, tumor necrosis factor-alpha (TNF- $\alpha$ ) or malondialdehyde (MDA) concentrations in control subjects and patients. ${ }^{24}$ In addition, MDA levels were similar in smokers and non-smokers. ${ }^{22}$ Acute ${ }^{25}$ or chronic ${ }^{26}$ smoking did not affect EBC IL-8 levels. Metabolomic fingerprints of smokers, patients with COPD and pulmonary Langerhans cell histiocytosis, who were current smokers with a significant smoking history, could be differentiated suggesting that smoking does not mask the specific disease metabolotypes. ${ }^{27}$

Effects of physiological variations and patientrelated activities on EBC markers in COPD have also been studied. $\mathrm{H}_{2} \mathrm{O}_{2}$ concentration showed diurnal variability in patients with COPD, ${ }^{28}$ and it was strongly affected by the respiratory pattern, necessitating the need for controlled breathing maneuvers in case-control studies. ${ }^{29}$ Exercise leads to a sustained elevation in $\mathrm{EBC} \mathrm{pH}$ of healthy subjects, ${ }^{30}$ and it also increases EBC $\mathrm{H}_{2} \mathrm{O}_{2}$ levels in COPD. ${ }^{31}$ It was, in addition, demonstrated that drinking sparkling water supplemented with sugar or coca cola in 1 hour prior to EBC collection influences $\mathrm{pH}$ values. 32

Gastro-oesophageal reflux disease (GORD) is a common comorbidity in obstructive lung diseases. Lower ${ }^{33}$ and similar ${ }^{34} \mathrm{EBC} \mathrm{pH}$ was also reported in patients suffering from concomitant COPD and GORD. In addition, EBC pepsin levels were significantly higher in those COPD patients who had reflux as reported by one study. 34 However, another group found no difference in EBC pepsin concentration in COPD patients with and without GORD. ${ }^{35}$

\section{Technical issues of sample collection and respiratory droplet dilution}

\section{Collection devices}

Several collection devices, either commercially available or custom-made, have been used for research and clinical purposes. These instruments differ from each other in many aspects including material of the condensing surface (e.g. plastic, Teflon, glass or aluminium), condensing temperature (between $-20{ }^{\circ} \mathrm{C}$ and $-80^{\circ} \mathrm{C}$ ), stability of condensing temperature during collection, portability, re-usability, ability to separately collect fractions during tidal breathing. Depending on their chemical properties, molecules in the condensate fluid are trapped in the various condensing systems differently. ${ }^{4}$ In line with this, coating the collection surface with albumin yielded a better mediator recovery. ${ }^{36}$ Inter-device differences in the detectability and quantity of total protein content, ${ }^{37,}, 38$ albumin, ${ }^{39}$ alpha-1-antitrypsin, ${ }^{38}$ 8-isoprostane, ${ }^{39,} 40 \mathrm{H}_{2} \mathrm{O}_{2},{ }^{40}$ cysteinyl leukotrienes (cys-LT), 37 interleukins (IL)-2, $-4,-5,-13,40$ tumour necrosis factor- $\alpha$ (TNF- $\alpha)^{40}$ and $\mathrm{pH}^{37,41-43}$ have been reported. In addition to the influence of the coating material, the condensing temperature also contributes to the variability in EBC markers, as shown for $\mathrm{pH}$ readings. ${ }^{37}$

\section{Dilution of respiratory droplets in $\mathrm{EBC}$}

Exhaled breath condensate is a very dilute liquid. More than $99 \%$ of its water content origi- 
nates from the alveolar space which mixes with the respiratory droplets liberated from the airway wall. Since the ratio of alveolar and bronchial water source is variable, the airway concentration of the investigated mediator cannot be estimated simply from its EBC content. Therefore, it is suggested to determine an indicator representing the rate of respiratory droplet dilution in each condensate sample. Such indicator needs to be reliably measurable in $\mathrm{EBC}$ and must have a known airway concentration. Methods developed to normalize EBC concentration for dilution include the measurement of exhaled ions,,${ }^{5,4}$ urea, ${ }^{44}$ proteins ${ }^{45}$ or conductance of lyophilized ${ }^{44}$ or vacuum evaporated 6,46 samples. Theoretically, dilution may affect the concentration of water-soluble non-volatile molecules and by assessing its magnitude the airway level of the mediator can be calculated from its concentration in EBC. 46,47 However, dilution influences EBC $\mathrm{pH}$ as well. 48 It is still strongly debated if EBC studies should routinely apply correction on dilution. ${ }^{4}$ Of note, no difference was shown in the magnitude of respiratory droplet dilution between COPD and health. ${ }^{49}$

\section{Difficulties of biomarker measurements in EBC}

Sensitivity and accuracy of detection methods used in EBC analysis

As breath condensate is a highly diluted solution, which contains the mediator of interest in small amounts, sensitive methods are required for detection and quantification. In addition, being a water-based solution, EBC is not an optimal matrix for most commercially available assay systems that are optimized for samples with more complex constituents. The high intra-subject and within-subject variation described for many EBC mediators can in part be attributed to an inappropriate choice of methods for detection. ${ }^{4,} 5$ Here, we enumerate advantages and disadvantages for exemplary assay systems, commonly used in studies on COPD.

It was elegantly shown that enzyme-linked immune assays (EIA), used for measuring cytokines in many past publications, can provide false positive mediator concentrations in $\mathrm{EBC}, 50$ as these systems are developed for detection in the complex matrices of serum, plasma or cell culture media. The authors suggest adjustment of EBC by adding a proteinacious lyophilized material to samples to prevent false detection signals in EIA. The lack of adjustment could be a reason for a high within-assay variability for EIA on $\mathrm{LTB}_{4}$ and 8-isoprostane, which showed that the mean coefficient of variation $(\mathrm{CV})$ in $\mathrm{EBC}$ samples was $18.2 \%$ and $29.2 \%$ in stable COPD. ${ }^{1}$ Similarly, the within-assay variability of cys-LT concentration in EBC from control volunteers was $19.6 \%{ }^{1}$

Malondialdehyde (MDA) was measured with high-pressure liquid chromatography and with the more sensitive method of liquid chromatography and tandem mass spectrometry. ${ }^{51,} 52 \mathrm{Al}-$ though the lower limit of detection was not reported for the latter method, it enabled the quantification of much lower concentrations.

Complex detection techniques allow multimarker screening of EBC with high sensitivity. Mass spectrometry-based measurement protocols for oxidative stress markers and leukotrienes could reach detection and quantification limits in the low $\mathrm{pg} / \mathrm{ml}$ range with $>90 \%$ accuracy in EBC from control subjects, ${ }^{53}, 54$ but data on COPD are still lacking. Additionally, a mass spectrometry protocol was developed for the measurement of adenosine and adenine purines accompanied with the detection of urea to assess dilution of ALF with good within-assay reproducibility. ${ }^{47}$ Metabolomic profiling in $\mathrm{EBC}$ has been performed with various methods. With NMR spectroscopy the fingerprint of patients with COPD could be distinguished from controls; 14,20 however, another group found that this method was not sensitive enough to pick up important EBC signals, and proposed a mass spectrometric protocol as the detection method. ${ }^{21}$

Concentration of EBC samples to increase biomarker levels

A main challenge for the reliable detection of EBC components is their low concentration in the sample. This could be overcome by sample concentration including lyophilisation, when all 
free water is removed from the frozen sample but solutes remain to be concentrated. ${ }^{2}$ This method has been successfully used to detect multiple cytokines with cytometric bead array in COPD patients 55 when samples were 40 times concentrated. Of note, cytokines could be detected only in a small fraction of concentrated EBC samples from controls and stable COPD patients, with a higher detection rate in exacerbated patients. Intra-assay and inter-assay reproducibility for the individual markers varied in $90-97 \%$ and 80 $93 \%$, respectively. It must be highlighted that after sample concentration cytokine concentrations in controls and stable patients were still around the manufacturer's assay detection limit; however, detection limits in EBC matrix have not been established.

Lyophilisation of pooled samples (600x concentration) enabled the detailed characterization of the EBC proteome; 13 nonetheless, a protocol for the concentration of individual samples should be developed for clinical studies. Similarly, oxidative stress molecules and leukotrienes could successfully and reliably be measured and quantified in lyophilised and concentrated EBC samples. ${ }^{53,}{ }^{54}$ As an alternative to lyophilisation, frozen samples can be evaporated in a vacuum system. ${ }^{6}$

\section{Stability of EBC markers during storage}

Data on biomarker stability are only scarcely available in COPD, and therefore mainly available findings of relevant mediators from control subjects are discussed below.

EBC $\mathrm{pH}$ was stable at room temperature for 3 hours, but within-sample variability increased when freezing samples for 3 months, but it was still comparable to within-sample variation in freshly collected EBC. ${ }^{56}$ Similarly, no significant influence of short- and long-term (from 3 months up to 2 years) storage on $\mathrm{EBC} \mathrm{pH}$ was found in samples collected from a control group of nonsmokers and smokers. ${ }^{57}$

EBC cys-LT concentration considerably decreased after 3 months of storage at $-80{ }^{\circ} \mathrm{C}$, which could be prevented by pretreatment of the sample with $0.2 \%$ formic acid in methanol following solid-phase extraction before freezing. However, mediator recovery showed high inter- subject variation, most probably due to inter- and intra-assay variability. Therefore this method for increasing marker stability was not advised by the authors. ${ }^{58}$

Stability of nitrite in EBC at room temperature was studied in children with respiratory diseases (asthma, cystic fibrosis). The mean CV for nitrite concentration after 1 and 3 hours of storage ranged $0-33 \% .{ }^{19}$ For optimal stability, samples should be kept cold $\left(<8{ }^{\circ} \mathrm{C}\right)$ and concentration of nitric oxides should be determined within 24 hours, or samples can be frozen, but repeated freeze-thaw cycles should be avoided before measurement. 15

MDA was stable for 2 weeks at $4^{\circ} \mathrm{C}$ in EBC collected from controls and patients with COPD. ${ }^{51}$

The addition of protein to EBC may prevent the decay of the marker of interest, however, it should be tested for each mediator. ${ }^{5}$

Intra-subject variability of $\mathrm{EBC}$ marker concentrations in COPD

Within-day and between day variabilities of EBC biomarkers measured in COPD are generally poor, and not systematically studied for all mediators.

Both within- and between-day variations in EBC $\mathrm{pH}$ of stable COPD patients were significant, largely exceeding intra-sample variability. ${ }^{56}$ The authors found no correlation between the degree of variability and clinical factors such as inhaled corticosteroid use, age and $\mathrm{FEV}_{1}$. The between-day variability of EBC $\mathrm{pH}$ was higher in current smokers than in non-smokers as assessed by six samplings in a 1-month period (mean variance $0.8 v s .0 .03$ ), with acute smoking significantly contributing to this variation. ${ }^{57}$

Concentration of $\mathrm{LTB}_{4}$ and 8-isoprostane in EBC as measured with EIA demonstrated a significant within-subject variability in stable COPD (within-day CV: $47.7 \%$ and $65.3 \%$, between-day CV: $75.7 \%$ and $79.1 \%$, respectively). ${ }^{1}$

On one hand, between-day variability of EBC MDA concentration was considerable (in the range of mean group values) in stable COPD when measured with high pressure liquid chromatography. ${ }^{51}$ On the other hand, when liquid chromatography and mass spectrometry was 
used, the between-day coefficient of variation of MDA concentration was only $8.2 \%$ in controls. 52 However, using the same detection technique the between-day mean coefficient of variation of a set of aldehydes in smokers ranged between $12.6 \%$ and $37.4 \%$, for MDA being $18.5 \% .^{2}$ Likewise, between-day $\mathrm{CV}$ of $\mathrm{EBC} \mathrm{H}_{2} \mathrm{O}_{2}$ concentration in stable COPD over 21-day interval was $45 \% .28$

Both within-day and between-day variability in EBC nitrite concentration were considerable in healthy adults, and within-day fluctuations in mediator concentration exceeded that of between-day. ${ }^{19}$ Between-day variability of EBC ATP concentration in control subjects was also high, showing a CV of $53 \%$ as measured using luminometry. 6 Nonetheless, the metabolomic profile of EBC as measured by NMR showed good within-days stability in COPD. ${ }^{14}$ This suggests that highly sensitive methods are needed to achieve good quality control in EBC analysis. Methodological challenges and pitfalls of sample collection and analysis in past COPD studies are highlighted in Table I.

\section{EBC biomarkers in COPD}

\section{Condensate fluid pH}

Airway acidity plays a key role in various elements of COPD pathology, including epithelial and ciliary dysfunction, bronchoconstriction, increased mucus production and impaired antimicrobial defence. ${ }^{59} \mathrm{EBC} \mathrm{pH}$ can easily be measured with blood gas analysers or $\mathrm{pH}$ electrodes. However, the $\mathrm{pH}$ value of the condensate fluid is determined not only by airway droplet acidity, but it is also affected by volatile gases and bases. Most notably, end tidal carbon dioxide influences condensate $\mathrm{pH}$ significantly. To overcome this effect, two methods were developed: Bubbling with an inert gas (i.e. argon) and the carbon dioxide loading technique. ${ }^{59}$ Due to considerable variation in $\mathrm{pH}$ values yielded by neat, argondeaerated and carbon dioxide-loaded sample measurements, results using different protocols should be compared with caution.

Both lower and similar EBC $\mathrm{pH}$ values were reported when stable COPD patients were compared to control subjects; $1,2,9,25,33,43,60,61$ however, control groups in these studies showed considerable heterogeneity consisting of nonsmokers, ex- or current smokers and a mixed population. This is highly important, as some publications demonstrated reduced $\mathrm{EBC} \mathrm{pH}$ value in smokers compared to non-smokers. ${ }^{25}, 43,60$ Supporting this, condensate $\mathrm{pH}$ was lower in COPD than in non-smoking controls, but not in relation to smokers. ${ }^{60}$ Interestingly, acute smoking did not affect EBC $\mathrm{pH} .{ }^{25}$

Analysing the relationship between EBC pH and measures of COPD severity, a direct relationship was reported with $\mathrm{FEV}_{1}$ and sputum neutrophilia, however other studies showed no correlation with lung function, $1,43,56,60,61$ sputum leukocyte counts, ${ }^{60}$ emphysematous phenotype 62 or exacerbation frequency. ${ }^{33} \mathrm{EBC} \mathrm{pH}$ was not different in COPD patients in exacerbation, ${ }^{25,43}$ nor did it change with exacerbation recovery. ${ }^{43}$

These data suggest that EBC $\mathrm{pH}$ is not a reliable disease marker in COPD, and it is not associated with clinical stability or a disease phenotype.

TABLE I.-Methodological difficulties and pitfalls during collection and analysis of EBC samples in past studies in COPD.

\begin{tabular}{|c|c|c|}
\hline Patient-related confounders & Sample collection and processing & Measurement of mediators \\
\hline $\begin{array}{l}\text { Variable smoking status of controls and } \\
\text { patients }\end{array}$ & Contaminants from inhaled air & $\begin{array}{l}\text { Lack of sample concentration required for } \\
\text { most commercial assays }\end{array}$ \\
\hline Possible effect of comorbidities & Effect of breathing pattern on biomarkers & $\begin{array}{l}\text { Detection methods not sensitive enough } \\
\text { for mediator detection }\end{array}$ \\
\hline $\begin{array}{l}\text { Food ingestion, drinking or exercise prior } \\
\text { to sampling }\end{array}$ & $\begin{array}{l}\text { Remnants of disinfectant on collection } \\
\text { device }\end{array}$ & $\begin{array}{l}\text { Measurement protocol not optimized for } \\
\text { EBC matrix }\end{array}$ \\
\hline Uncontrolled activity of oral bacteria & $\begin{array}{l}\text { Not ideal collection surface and } \\
\text { temperature }\end{array}$ & $\begin{array}{l}\text { Variable and high within- and between- } \\
\text { subject variation }\end{array}$ \\
\hline Presence of upper airway inflammation & $\begin{array}{l}\text { External contamination during } \\
\text { processing and measurement }\end{array}$ & $\begin{array}{l}\text { No systematic control for mediator } \\
\text { contamination outside the lower airways }\end{array}$ \\
\hline
\end{tabular}




\section{Markers of oxidative stress}

COPD is characterised by enhanced oxidative stress originating from exogenous factors (i.e. smoking, hypoxia) as well as endogenous burden (reactive oxygen species generated by inflammatory cells). Numerous studies have aimed to analyse stable markers of oxidative stress in EBC, most notably $\mathrm{H}_{2} \mathrm{O}_{2}, 8$-isoprostane and malondialdehyde.

Previous studies reported contradictory findings regarding a change in $\mathrm{EBC} \mathrm{H}_{2} \mathrm{O}_{2}$ concentration in stable COPD compared to controls, 1, 22, 61, 63 and there was a significant indirect relationship with $\mathrm{FEV}_{1}$ reported by some, but not all studies. ${ }^{1,22,}{ }^{61} \mathrm{In}$ addition, $\mathrm{H}_{2} \mathrm{O}_{2}$ levels were related to symptoms burden as assessed with the COPD Assessment Test. ${ }^{61}$ Compared to stable disease, a further elevation in $\mathrm{EBC}_{2} \mathrm{O}_{2}$ concentrations was reported during exacerbation, ${ }^{64}$ with significant reduction with resolution. ${ }^{65}$ However, another study noted no change during recovery. ${ }^{66}$ Treatment with inhaled corticosteroids decreased EBC $\mathrm{H}_{2} \mathrm{O}_{2}$ levels in one, ${ }^{67}$ but not in another study. 68

EBC 8-isoprostane levels were elevated in stable COPD. ${ }^{65,69}$ There was a further increase during exacerbation, ${ }^{26,70}$ and it decreased with resolution. ${ }^{65}$ However, the effect of smoking needs to be considered when interpreting data. Elevated, but also unaltered 8-isoprostane concentrations were reported in smokers. ${ }^{22,} 26$ In addition, 8-isoprostane was associated with smoking intensity in COPD. ${ }^{71}$ In line with this, 8 -isoprostane levels were increased in COPD compared to non-smokers without a significant difference when comparing with smokers without COPD. ${ }^{22}$ Analyzing the measures of COPD severity, a significant correlation was noted between EBC 8-isoprostane concentration and the degree of emphysema; ${ }^{2}$ however, this has not been confirmed by another study. ${ }^{62}$ There was an association with lung function; ${ }^{71}$ however, others reported no correlation between this mediator and disease severity. 22,69 In addition, high EBC 8-isoprostane levels were associated with dynamic hyperinflation, ${ }^{71}$ high BODE Index ${ }^{71}$ and low arterial pressure of oxygen. ${ }^{71}$ There was no difference in EBC 8-isoprostane levels between COPD patients with and without cardiovascular disease. ${ }^{72}$ Mediator concentration did not change following inhaled treatment with either corticosteroid ${ }^{73}$ or tiotropium. ${ }^{74}$

The level of MDA was increased in COPD compared to controls and also in relation to patients with asthma and bronchiectasis, ${ }^{52,63}$ and significantly correlated with lung function in COPD. ${ }^{63}$ However, other studies reported no difference. ${ }^{22,} 51$ There was no difference in MDA levels between stable and exacerbated COPD patients. ${ }^{51}$

Hydrogen peroxide and 8-isoprostane concentration is increased in EBC in stable COPD, and might reflect disease activity, but they do not seem to respond to inhaled treatment. The clinical relevance of measuring EBC MDA concentration in COPD is questionable.

\section{Markers of nitrative stress}

Nitric oxide (NO), a free radical gas, is generated by nitric oxide synthases in the airway epithelium and inflammatory cells. In the presence of superoxide anion, a mediator in oxidative stress, NO is rapidly converted into peroxynitrate, which via nitration damages proteins to form nitrosothiol components. Alternatively, $\mathrm{NO}$ can be oxidized into nitrite $\left(\mathrm{NO}_{2}^{-}\right)$and nitrate $\left(\mathrm{NO}_{3}\right)$. Peroxynitrate, nitrosothiols and nitrate/nitrite can be measured in EBC to assess the burden of airway nitrative stress.

Nitrate concentration was not different between stable patients and control subjects or between stable and exacerbated patients. ${ }^{1,18}$ Some authors suggested that the high variability in EBC nitrate concentrations was related to contamination during sample collection. On the contrary, nitrite concentration was increased in COPD and showed a positive correlation with disease severity. 55 Another study confirmed elevated nitrite concentration in stable COPD compared to never smokers and smokers, ${ }^{2}$ but it was contradicted by the finding that elevated nitrite concentration was observed only in exacerbated patients, but not in stable condition. ${ }^{18}$ Furthermore, the cumulative measurement of nitrite/nitrate (nitric oxides) showed similar concentrations in patients and controls. There was no difference either when groups were subdivided into smokers and 
ex-smokers, and ICS therapy was not associated with altered mediator concentration either. ${ }^{75} \mathrm{~A}$ novel fast method of capillary electrophoresis could detect increased concentrations of both nitrate and nitrite in EBC from patients with COPD compared to young, non-smoking controls in a pilot study. ${ }^{76}$ This was also shown by another study using a different detection method. ${ }^{77}$ In addition, EBC nitrosothiol concentration was elevated in ex-smoking COPD patients compared to non-smoking controls, but not to smokers. ${ }^{2}$ Furthermore, increased EBC nitrosothiol level was reported in retired coal workers with COPD compared to those with a similar history of inhaled exposure but no COPD. ${ }^{63}$

Measurement of nitrative stress markers are sensitive to external contamination, and sensitive detection methods are needed for reliable assessment.

\section{Arachidonic acid metabolites}

Arachidonic acid metabolites, including prostanoids, tromboxanes and leukotrienes, are involved in airway inflammation characterizing COPD. They were investigated in EBC either separately with EIAs or using complex analytics, such as mass spectrometry. The latter technique provided evidence of altered profile of arachidonic acid metabolites in COPD. 78

The most frequently investigated arachidonic acid metabolite in EBC is $\mathrm{LTB}_{4}$, which is a potent chemoattractant for neutrophil cells. All studies showed elevated EBC $\mathrm{LTB}_{4}$ concentrations in COPD compared to controls. ${ }^{65,}$, 72, 78-80 Although there was no further increase in mediator concentration during exacerbation, ${ }^{80} \mathrm{LTB}_{4}$ level decreased during recovery from a relapse. ${ }^{65}, 80 \mathrm{In}$ addition, no difference in $\mathrm{EBC} \mathrm{LTB}_{4}$ levels was reported between COPD patients with and without cardiovascular disease. ${ }^{72} \mathrm{EBC}^{\mathrm{LTB}} \mathrm{C}_{4}$ concentration was not altered by inhaled corticosteroid (ICS) treatment. ${ }^{73}$

Prostaglandin E2 (PGE2) pathway is implicated in the resolution of airway inflammation. Interestingly, higher EBC PGE2 concentrations were reported in COPD 65, 78, 79 compared to health without a change during COPD acute exacerbation. ${ }^{65}$

EBC cys-LT levels were elevated in patients with COPD compared to controls, ${ }^{65}$ while no difference was found for other lipid mediators such as $\mathrm{LTE}_{4}$ or PGD2-methoxime. ${ }^{79}$ Cys-LT concentration was reduced in convalescence of a COPD exacerbation, ${ }^{65}$ but it did not respond to therapy with ICS. ${ }^{73}$ Thromboxane B2 was not detectable in $\mathrm{EBC}$ using EIA. ${ }^{79}$

Among the arachidonic acid metabolites EBC $\mathrm{LTB}_{4}$ is the most studied mediator, which seems to be a marker for monitoring airway inflammation; ${ }^{11}$ however, salivary contamination is a potential confounder, which should be systematically controlled in studies. Profiling of metabolites using a mass spectrometry-based approach might aid the reliable detection and better interpretation of the role of arachidonic acid substances in COPD.

\section{Proteins}

A plethora of proteins, including cytokines, chemokines, enzymes and soluble receptors, suspected of involvement in airway inflammation in COPD, were detected in condensate fluid as single markers, mostly measured with immunoassays. In general, the results of EBC protein measurements are very variable and contradictory, possibly due to very low mediator concentrations and methodological issues discussed above.

The concentration of IL-1 $\beta$ in EBC was higher in COPD than in non-smokers but lower than in smokers, with no correlation with lung function. ${ }^{55}$ Increased EBC IL-6 level was measured in COPD by some authors; ${ }^{81}$ however, another study showed a lower concentration of this cytokine. .5 Treatment with tiotropium did not affect exhaled IL-6 levels. ${ }^{74}$ Similar ${ }^{25}$ and lower ${ }^{55}$ levels of IL-8 were reported in stable COPD compared to health. There was a significant correlation between IL-8 and lung function in one study but another reported no correlation. ${ }^{82}$ IL-8 levels significantly increased during exacerbation in some 26,83 and remained unchanged in other ${ }^{25}$ studies. IL-10 was lower in COPD compared to smokers, ${ }^{82}$ however another study showed no difference. ${ }^{55}$ IL-12 was increased in COPD; 84 however, another study reported lower levels of IL-12p70 compared to smokers. ${ }^{82}$ There was no correlation with lung function. 82

Studies on the pro-inflammatory cytokine 
TNF- $\alpha$ also reported conflicting findings. Higher, 81 similar, 83,85 or even lower 55,82 levels of EBC TNF- $\alpha$ were shown in COPD. Cytokine concentration did not correlate with lung function 82,85 and there was no difference in TNF- $\alpha$ in emphysema-dominant and non-emphysematous COPD patients. ${ }^{62}$ Treatment with tiotropium 74 did not affect TNF- $\alpha$ levels in COPD patients. Furthermore, increased and unchanged concentrations of TNF- $\alpha$ were also reported during exacerbation. 83,85

There was no difference in the level of GRO $\alpha$ or CXCL1, a chemoattractant for neutrophils, between healthy and stable COPD subjects, ${ }^{80}$ however another study reported lower levels in diseased subjects than controls. ${ }^{86}$ Although there was no difference in EBC GRO $\alpha$ levels between stable and exacerbated patients, ${ }^{80}$ the concentration the chemokine decreased during recovery from a flare-up. ${ }^{80}$

Surfactants are associated with host defence of the lung, which is compromised in COPD. In line with this, a study demonstrated lower levels of surfactant protein A (SP-A) in COPD compared to health, which directly correlated to lung function. ${ }^{87}$ However, a change in EBC SP-A concentration in COPD was not confirmed by another group. ${ }^{23}$ Similarly, no difference in EBC surfactant protein B was measured. ${ }^{23}$

Markers of recruitment and activation of neutrophil, monocyte and macrophages could be detected in the condensate fluid. Significantly elevated EBC concentration of myeloperoxidase, ${ }^{36}$ secretory leukocyte protease inhibitor, ${ }^{36}$ macrophage migration inhibitory factor, ${ }^{84}$ RANTES, ${ }^{84}$ sICAM-1 ${ }^{84,} 88$ were found in COPD. No change in the EBC level of monocyte chemotactic protein- $1,86 \mathrm{sVCAM} 1,{ }^{88} \mathrm{sE}$-selectin, ${ }^{88}$ vascular endothelial growth factor, 83 fibroblast growth factor- $\beta,{ }^{83}$ angiogenin, ${ }^{83}$ periostin ${ }^{89}$ or alpha1 -antitrypsin 90 was reported. However, alpha1-antitrypsin increased during exacerbation..$^{90}$ On the other hand, EBC IFN- $\gamma$ concentration decreased in COPD. ${ }^{36}$

Matrix metalloproteases (MMP) degrade the pulmonary extracellular matrix, contributing to parenchymal destruction. Exhaled MMP8 concentration was lower, ${ }^{91}$ while the concentrations of MMP9 and the inhibitor of metalloprotein- ase-1 were increased in COPD, and heightened during exacerbation. ${ }^{92}$ However, EBC MMP9 concentration was below the detection limit in another study using a similar EIA platform for detection..$^{91}$

Detection of proteins including cytokines, chemokines and circulating receptors in EBC seems unreliable with immune assays used in previous reports, as implicated by the contradictory findings on these markers in stable and exacerbated COPD.

\section{"Omics" profiles detected in EBC}

The "omics" technology offers the potential to detect a multiparametric response to physiological and pathophysiological stimuli in health and disease. It can generate a profile of multiple variables which have the potential to better identify disease mechanisms than single markers. The main advantage of this approach is its hypothesis-free nature, which gives ground to the identification of novel substances, previously not linked with disease pathomechanism. The application of "omics" approach in EBC has mostly included analysis of metabolic compounds (metabolomics) and proteins (proteomics). Despite the current enthusiasm, it is worth taking into account that the inherent methodology limitations such as dilution and not least mixed contribution from upper airways, mouth and salivary glands are likely to impact "omics" as well.

Metabolomic fingerprints of EBC generated by NMR spectroscopy followed by cluster analysis could differentiate patients with COPD from control smokers with very good accuracy $\left(\mathrm{r}^{2}=99.9 \%\right) .{ }^{14,} 20$ In a very recent publication, NMR spectra obtained from patients with newly diagnosed COPD or asthma could distinguish between patients. ${ }^{20} \mathrm{~A}$ higher concentration of ethanol and methanol, while lower levels of formate and acetone/acetion were found in COPD. Their model was validated in a second set of patients with a sensitivity of $92.3 \%$ and a specificity of $95 \%$. Interestingly, metabolomic fingerprinting of EBC could identify the emphysematous subgroup within a cohort of COPD patients..$^{93}$ In a pilot study, a method of on-site, fast capillary electrophoretic analysis of EBC allowed the detection of multiple metabolic products including acetate, 
lactate, propionate and butyrate. ${ }^{76}$ Concentrations of acetate and propionate were increased in COPD compared to controls, however clinical characteristics (age, smoking history) were not matched between the groups.

A protocol of using liquid chromatography and mass spectrometry for proteomic analysis was developed. ${ }^{4}$ The same group identified profiles of sets of proteins which identified COPD patients without emphysema, patients with emphysema associated with alpha-1-antitrypsin deficiency and control subjects. ${ }^{95}$ They partly validated these findings using other detection techniques. Some identified proteins had not been previously linked with the diseases, giving new insight into disease pathomechanism. Importantly, $>100$ proteins were reproducibly identified in EBC from control subjects, making the first step to characterize the EBC proteome in health. ${ }^{13}$

Metabolomic and proteomic analysis of EBC samples needs sample preparation, advanced detection techniques and complex analysis algorithms, which could limit their use in clinical practice. However, optimized measurement protocols may facilitate understanding disease mechanisms and broaden the potential of EBC analysis.

\section{Purinergic mediators}

ATP is released from every cell to activate purinergic $\mathrm{P} 2$ receptors in an autocrine/paracrine fashion. ATP can be converted enzymatically into adenosine triphosphate (ADP), adenosine monophosphate (AMP) and then into adenosine, mediators which also activate $\mathrm{P} 2$ and $\mathrm{P} 1$ receptors. Receptor activation on epithelial and inflammatory cells within the airways induce ciliary beating, promotes inflammation but can also be involved in the resolution of inflammatory processes.

ATP concentration in EBC did not change in COPD patients with an acute severe exacerbation compared to smoking and non-smoking controls, and it was unchanged during convalescence. ${ }^{6}$ However, adenosine/urea and AMP/urea ratios were increased in stable COPD and correlated with $\mathrm{FEV}_{1} \%$ predicted, suggesting that ATP degrades fast in airways, but its products can be used for monitoring of airway inflammation. ${ }^{47}$

\section{Nucleic acids}

It can be postulated that exhaled particles contain live or dead pathogens originating from the lower airways, and they might also carry very small amounts of DNA and RNA fragments from resident and inflammatory cells within the lungs.

Bacterial DNA, but not viral RNA, was successfully detected in EBC from exacerbated COPD patients. The profile of airway microorganisms in EBC did not correlate with that found in sputum, suggesting different sampling sites for sputum and $\mathrm{EBC}$ and questioning the clinical relevance of analysing the condensate fluid for airway pathogens in COPD. ${ }^{96}$

The ratio of mitochondrial DNA to nuclear DNA, as a marker of oxidative stress, was found to be elevated in EBC from patients with stable COPD compared to control subjects. ${ }^{97}$ However, this study was biased by the unmatched smoking history between patients and controls.

MicroRNAs are small, non-coding nucleotides, which modify post-transcriptional gene expression and they are dysregulated under inflammatory conditions including asthma and COPD. MicroRNAs can be found intracellularly and extracellularly in bodily fluids. The expression of 39 microRNAs was successfully measured in EBC from stable patients with allergic asthma, COPD and control subjects (unmatched smoking history to COPD patients). The authors identified 9 principal components from the expression data, which could distinguish controls from patient groups, but not patients with asthma from those with COPD. ${ }^{98} \mathrm{FEV}_{1}$ was a major confounder in the analysis.

The number of studies on nucleic acids in EBC from patients with COPD is very limited. These observations suggest very low DNA and RNA content in EBC, and preliminary findings need further validation.

\section{Conclusions}

The collection of exhaled breath condensate is completely non-invasive, easily repeatable within short time intervals, and constituents of the condensate fluid partly originate from the lower airways, showing potential for disease monitor- 
ing in COPD. A broad spectrum of markers has been analyzed in $\mathrm{EBC}$, which are mostly related to ongoing airway inflammation, including $\mathrm{pH}$ values of the condensate fluid, oxidative/nitrative stress molecules, cytokines, chemokines, arachidonic acid products or nucleic acids. Presently, no single EBC biomarker has been validated to identify clinical phenotypes, predict disease relapse or progression in COPD. This can be explained by our lack of knowledge of EBC formation, unstandardized study designs between research groups with variable collection setups, insensitive and inappropriate detection methods to analyze the highly diluted condensate fluid and limited study sample size with no data validation. However, multimarker measurements in EBC using sensitive and high-throughput analytical approaches with preferably fast-track data interpretation algorithms may aid better understanding the undoubtedly complex pathomechanism of COPD and facilitate finding the role of this approach for clinical practice.

It may also be worth considering whether some of the previously findings could be re-interpreted. As a principle, it is not necessarily interesting whether or not an EBC biomarker varies between COPD patients and smokers without airflow limitation - spirometry will be used for this separation. What we need are biomarkers that can differentiate "active COPD" from fixed airflow limitation caused by historic exposures ("burnt-out" disease) and possibly also differentiate the various trajectories leading to COPD. ${ }^{99}$

Potential considerations for future directions, aiming at clinical application of EBC analysis in COPD, are listed in Table II.

\section{References}

1. Borrill ZL, Roy K, Singh D. Exhaled breath condensate biomarkers in COPD. Eur Respir J 2008;32:472-86.

2. Grob NM, Aytekin M, Dweik RA. Biomarkers in exhaled breath condensate: a review of collection, processing and analysis. J Breath Res 2008;2:037004.

3. Kuban P, Foret F. Exhaled breath condensate: determination of non-volatile compounds and their potential for clinical diagnosis and monitoring. A review. Anal Chim Acta 2013;805:1-18.

4. Horvath I, Barnes PJ, Loukides S, Sterk PJ, Hogman M, Olin AC, et al. A European Respiratory Society technical standard: exhaled biomarkers in lung disease. Eur Respir J 2017;49.

5. Horvath I, Hunt J, Barnes PJ, Alving K, Antczak A, Baraldi E, et al. Exhaled breath condensate: methodological recommendations and unresolved questions. Eur Respir J 2005;26:523-48.

6. Lazar Z, Huszar E, Kullmann T, Barta I, Antus B, Bikov A, et al. Adenosine triphosphate in exhaled breath condensate of healthy subjects and patients with chronic obstructive pulmonary disease. Inflamm Res 2008;57:367-73.

7. Marteus H, Tornberg DC, Weitzberg E, Schedin U, Alving $\mathrm{K}$. Origin of nitrite and nitrate in nasal and exhaled breath condensate and relation to nitric oxide formation. Thorax 2005;60:219-25.

8. Johnson GR, Morawska L. The mechanism of breath aerosol formation. J Aerosol Med Pulm Drug Deliv 2009;22:229-37.

9. Effros RM, Casaburi R, Su J, Dunning M, Torday J, Biller $\mathrm{J}$, et al. The effects of volatile salivary acids and bases on exhaled breath condensate $\mathrm{pH}$. Am J Respir Crit Care Med 2006; 173:386-92.

10. Bikov A, Pako J, Montvai D, Kovacs D, Koller Z, Losonczy $\mathrm{G}$, et al. Exhaled breath condensate $\mathrm{pH}$ decreases following oral glucose tolerance test. J Breath Res 2015;9:047112.

11. Gaber F, Acevedo F, Delin I, Sundblad BM, Palmberg L, Larsson $\mathrm{K}$, et al. Saliva is one likely source of leukotriene B4 in exhaled breath condensate. Eur Respir J 2006;28:1229-35.

12. Griese M, Noss J, Von Bredow C. Protein pattern of exhaled breath condensate and saliva. Proteomics 2002;2:690-6.

13. Lacombe M, Marie-Desvergne $\mathrm{C}$, Combes $\mathrm{F}$, Kraut A, Bruley C, Vandenbrouck Y, et al. Proteomic characterization of human exhaled breath condensate. J Breath Res 2018;12:021001.

14. De Laurentiis G, Paris D, Melck D, Maniscalco M, Mar-

TABLE II.-Future directions for the application of EBC analysis in clinical practice.

\begin{tabular}{|c|c|c|}
\hline Sample collection & Measurements in EBC & Data interpretation \\
\hline $\begin{array}{l}\text { Collection surfaces and temperature } \\
\text { optimized for the markers of interest }\end{array}$ & Favoring multimarker profiling & $\begin{array}{l}\text { Development of analytical protocols for } \\
\text { multiparametric profiling }\end{array}$ \\
\hline Short collection time & $\begin{array}{l}\text { Routine concentration of individual } \\
\text { samples (when needed) }\end{array}$ & $\begin{array}{l}\text { Data acquisition from a large pool of } \\
\text { controls and patients }\end{array}$ \\
\hline $\begin{array}{l}\text { Standardized sample collection } \\
\text { procedures among international centres }\end{array}$ & $\begin{array}{l}\text { Development and standardization of } \\
\text { sensitive and high-throughput detection } \\
\text { techniques }\end{array}$ & $\begin{array}{l}\text { Integration of standardized results into } \\
\text { international data bases }\end{array}$ \\
\hline Disposable chamber for sample collection & $\begin{array}{l}\text { External validation of markers/profiles in } \\
\text { controls and patients }\end{array}$ & $\begin{array}{c}\text { Generation of normal ranges for } \\
\text { mediators and marker profiles }\end{array}$ \\
\hline Portable collection devices & Fast-track result acquisition & \\
\hline $\begin{array}{l}\text { Development for potential as home } \\
\text { monitoring device }\end{array}$ & $\begin{array}{l}\text { Integration of detection setup to } \\
\text { collection device }\end{array}$ & \\
\hline
\end{tabular}


sico S, Corso G, et al. Metabonomic analysis of exhaled breath condensate in adults by nuclear magnetic resonance spectroscopy. Eur Respir J 2008;32:1175-83.

15. Chladkova J, Krcmova I, Chladek J, Cap P, Micuda S, Hanzalkova Y. Validation of nitrite and nitrate measurements in exhaled breath condensate. Respiration 2006;73:173-9.

16. Peters S, Kronseder A, Karrasch S, Neff PA, Haaks M, Koczulla AR, et al. Hydrogen peroxide in exhaled air: a source of error, a paradox and its resolution. ERJ Open Res 2016;2.

17. Hoffmann HJ, Tabaksblat LM, Enghild JJ, Dahl R. Human skin keratins are the major proteins in exhaled breath condensate. Eur Respir J 2008;31:380-4.

18. Rihak V, Zatloukal P, Chladkova J, Zimulova A, Havlinova Z, Chladek J. Nitrite in exhaled breath condensate as a marker of nitrossative stress in the airways of patients with asthma, COPD, and idiopathic pulmonary fibrosis. J Clin Lab Anal 2010;24:317-22.

19. Vogelberg C, Kahlert A, Wurfel C, Marx K, Bohm A, Range U, et al. Exhaled breath condensate nitrite--methodological problems of sample collection. Med Sci Monit 2008;14:CR416-22.

20. Motta A, Paris D, Melck D, De Laurentiis G, Maniscalco $\mathrm{M}$, Sofia M, et al. Nuclear magnetic resonance-based metabolomics of exhaled breath condensate: methodological aspects. Eur Respir J 2012;39:498-500.

21. Izquierdo-Garcia JL, Peces-Barba G, Heili S, Diaz R, Want E, Ruiz-Cabello J. Is NMR-based metabolomic analysis of exhaled breath condensate accurate? Eur Respir J 2011;37:468-70.

22. Inonu H, Doruk S, Sahin S, Erkorkmaz U, Celik D, Celikel S, et al. Oxidative stress levels in exhaled breath condensate associated with COPD and smoking. Respir Care 2012;57:413-9.

23. Mutti A, Corradi M, Goldoni M, Vettori MV, Bernard A, Apostoli P. Exhaled metallic elements and serum pneumoproteins in asymptomatic smokers and patients with COPD or asthma. Chest 2006;129:1288-97.

24. Maskey-Warzechowska M, Nejman-Gryz P, Osinka K, Lis P, Malesa K, Gorska K, et al. Acute Response to Cigarette Smoking Assessed in Exhaled Breath Condensate in Patients with Chronic Obstructive Pulmonary Disease and Healthy Smokers. Adv Exp Med Biol 2017;944:73-80.

25. Koczulla AR, Noeske S, Herr C, Jorres RA, Rommelt H, Vogelmeier C, et al. Acute and chronic effects of smoking on inflammation markers in exhaled breath condensate in current smokers. Respiration 2010;79:61-7.

26. Mazur W, Stark H, Sovijarvi A, Myllarniemi M, Kinnula VL. Comparison of 8-isoprostane and interleukin-8 in induced sputum and exhaled breath condensate from asymptomatic and symptomatic smokers. Respiration 2009;78:209-16.

27. De Laurentiis G, Paris D, Melck D, Montuschi P, Maniscalco M, Bianco A, et al. Separating smoking-related diseases using NMR-based metabolomics of exhaled breath condensate. J Proteome Res 2013;12:1502-11.

28. Van Beurden WJ, Dekhuijzen PN, Harff GA, Smeenk FW. Variability of exhaled hydrogen peroxide in stable COPD patients and matched healthy controls. Respiration 2002;69:211-6

29. Gajdocsi R, Bikov A, Antus B, Horvath I, Barnes PJ, Kharitonov SA. Assessment of reproducibility of exhaled hydrogen peroxide concentration and the effect of breathing pattern in healthy subjects. J Aerosol Med Pulm Drug Deliv 2011;24:271-5.

30. Bikov A, Lazar Z, Schandl K, Antus BM, Losonczy G,
Horvath I. Exercise changes volatiles in exhaled breath assessed by an electronic nose. Acta Physiol Hung 2011;98:321-8.

31. Mercken EM, Gosker HR, Rutten EP, Wouters EF, Bast A, Hageman GJ, et al. Systemic and pulmonary oxidative stress after single-leg exercise in COPD. Chest 2009;136:1291-300.

32. Kullmann T, Barta I, Antus B, Horvath I. Drinking influences exhaled breath condensate acidity. Lung 2008;186:263-8.

33. Terada K, Muro S, Sato S, Ohara T, Haruna A, Marumo S, et al. Impact of gastro-oesophageal reflux disease symptoms on COPD exacerbation. Thorax 2008;63:951-5.

34. Timms C, Thomas PS, Yates DH. Detection of gastrooesophageal reflux disease (GORD) in patients with obstructive lung disease using exhaled breath profiling. J Breath Res 2012;6:016003

35. Lee AL, Button BM, Denehy L, Roberts S, Bamford T, $\mathrm{Mu}$ FT, et al. Exhaled Breath Condensate Pepsin: Potential Noninvasive Test for Gastroesophageal Reflux in COPD and Bronchiectasis. Respir Care 2015;60:244-50.

36. Tateosian NL, Costa MJ, Guerrieri D, Barro A, Mazzei JA, Eduardo Chuluyan H. Inflammatory mediators in exhaled breath condensate of healthy donors and exacerbated COPD patients. Cytokine 2012;58:361-7.

37. Czebe K, Barta I, Antus B, Valyon M, Horvath I, Kullmann $\mathrm{T}$. Influence of condensing equipment and temperature on exhaled breath condensate $\mathrm{pH}$, total protein and leukotriene concentrations. Respir Med 2008;102:720-5.

38. Huttmann EM, Greulich T, Koepke J, Nell C, Hattesohl A, Schmid S, et al. Correction: Comparison of Two Devices and Two Breathing Patterns for Exhaled Breath Condensate Sampling. PLoS One 2016;11:e0152620.

39. Rosias PP, Robroeks CM, Niemarkt HJ, Kester AD, Vernooy JH, Suykerbuyk J, et al. Breath condenser coatings affect measurement of biomarkers in exhaled breath condensate. Eur Respir J 2006;28:1036-41.

40. Rosias PP, Robroeks CM, Kester A, Den Hartog GJ, Wodzig WK, Rijkers GT, et al. Biomarker reproducibility in exhaled breath condensate collected with different condensers. Eur Respir J 2008;31:934-42.

41. Leung TF, Li CY, Yung E, Liu EK, Lam CW, Wong $\mathrm{GW}$. Clinical and technical factors affecting $\mathrm{pH}$ and other biomarkers in exhaled breath condensate. Pediatr Pulmonol 2006;41:87-94.

42. Prieto L, Ferrer A, Palop J, Domenech J, Llusar R, Rojas R. Differences in exhaled breath condensate $\mathrm{pH}$ measurements between samples obtained with two commercial devices. Respir Med 2007;101:1715-20.

43. Antus B, Barta I, Kullmann T, Lazar Z, Valyon M, Horvath $\mathrm{I}$, et al. Assessment of exhaled breath condensate $\mathrm{pH}$ in exacerbations of asthma and chronic obstructive pulmonary disease: A longitudinal study. Am J Respir Crit Care Med 2010;182:1492-7.

44. Effros RM, Biller J, Foss B, Hoagland K, Dunning MB, Castillo $\mathrm{D}$, et al. A simple method for estimating respiratory solute dilution in exhaled breath condensates. Am J Respir Crit Care Med 2003;168:1500-5.

45. Gessner C, Kuhn H, Seyfarth HJ, Pankau H, Winkler J, Schauer J, et al. Factors influencing breath condensate volume. Pneumologie 2001;55:414-9.

46. Lazar Z, Cervenak L, Orosz M, Galffy G, Komlosi ZI, Bikov A, et al. Adenosine triphosphate concentration of exhaled breath condensate in asthma. Chest 2010;138:536-42.

47. Esther CR Jr, Lazaar AL, Bordonali E, Qaqish B, Boucher RC. Elevated airway purines in COPD. Chest 2011;140:954-60. 
48. Bikov A, Galffy G, Tamasi L, Lazar Z, Losonczy G, Horvath I. Exhaled breath condensate $\mathrm{pH}$ is influenced by respiratory droplet dilution. J Breath Res 2012;6:046002.

49. Effros RM, Peterson B, Casaburi R, Su J, Dunning M, Torday $\mathrm{J}$, et al. Epithelial lining fluid solute concentrations in chronic obstructive lung disease patients and normal subjects. J Appl Physiol (1985) 2005;99:1286-92.

50. Hom S, Walsh B, Hunt J. Matrix effect in exhaled breath condensate interferon-gamma immunoassay. J Breath Res 2008;2:041001.

51. Antus B, Harnasi G, Drozdovszky O, Barta I. Monitoring oxidative stress during chronic obstructive pulmonary disease exacerbations using malondialdehyde. Respirology 2014;19:74-9.

52. Corradi M, Rubinstein I, Andreoli R, Manini P, Caglieri A, Poli D, et al. Aldehydes in exhaled breath condensate of patients with chronic obstructive pulmonary disease. Am J Respir Crit Care Med 2003;167:1380-6.

53. Janicka M, Kubica P, Kot-Wasik A, Kot J, Namiesnik J. Sensitive determination of isoprostanes in exhaled breath condensate samples with use of liquid chromatography-tandem mass spectrometry. J Chromatogr B Analyt Technol Biomed Life Sci 2012;893-894:144-9.

54. Syslova K, Kacer P, Vilhanova B, Kuzma M, Lipovova P, Fenclova Z, et al. Determination of cysteinyl leukotrienes in exhaled breath condensate: method combining immunoseparation with LC-ESI-MS/MS. J Chromatogr B Analyt Technol Biomed Life Sci 2011;879:2220-8.

55. Gessner C, Hammerschmidt S, Kuhn H, Hoheisel G, Gillissen A, Sack U, et al. Breath condensate nitrite correlates with hyperinflation in chronic obstructive pulmonary disease. Respir Med 2007;101:2271-8.

56. Borrill Z, Starkey C, Vestbo J, Singh D. Reproducibility of exhaled breath condensate $\mathrm{pH}$ in chronic obstructive pulmonary disease. Eur Respir J 2005;25:269-74.

57. Do R, Bartlett KH, Chu W, Dimich-Ward H, Kennedy SM. Within- and between-person variability of exhaled breath condensate $\mathrm{pH}$ and $\mathrm{NH} 4+$ in never and current smokers. Respir Med 2008;102:457-63.

58. Ohanian AS, Zimmerman J, Debley JS. Effects of sample processing, time and storage condition on cysteinyl leukotrienes in exhaled breath condensate. J Breath Res 2010;4:046002.

59. Bikov A, Horvath I. Methodological Issues and Possible Clinical Implications for Exhaled Breath Condensate $\mathrm{pH}$ in Asthma. Curr Top Med Chem 2016;16:1550-60.

60. Macnee W, Rennard SI, Hunt JF, Edwards LD, Miller BE, Locantore NW, et al. Evaluation of exhaled breath condensate $\mathrm{pH}$ as a biomarker for COPD. Respir Med 2011;105:1037-45.

61. Murata K, Fujimoto K, Kitaguchi Y, Horiuchi T, Kubo $\mathrm{K}$, Honda $\mathrm{T}$. Hydrogen peroxide content and $\mathrm{pH}$ of expired breath condensate from patients with asthma and COPD. COPD 2014;11:81-7.

62. Papaioannou AI, Mazioti A, Kiropoulos T, Tsilioni I, Koutsokera A, Tanou K, et al. Systemic and airway inflammation and the presence of emphysema in patients with COPD. Respir Med 2010;104:275-82.

63. Lee JS, Shin JH, Hwang JH, Baek JE, Choi BS. Malondialdehyde and 3-nitrotyrosine in exhaled breath condensate in retired elderly coal miners with chronic obstructive pulmonary disease. Saf Health Work 2014;5:91-6.

64. Dekhuijzen PN, Aben KK, Dekker I, Aarts LP, Wielders PL, Van Herwaarden CL, et al. Increased exhalation of hydrogen peroxide in patients with stable and unstable chronic obstructive pulmonary disease. Am J Respir Crit Care Med 1996;154:813-6.

65. Antczak A, Ciebiada M, Pietras T, Piotrowski WJ, Kurmanowska Z, Gorski P. Exhaled eicosanoids and biomarkers of oxidative stress in exacerbation of chronic obstructive pulmonary disease. Arch Med Sci 2012;8:277-85.

66. Van Beurden WJ, Smeenk FW, Harff GA, Dekhuijzen PN. Markers of inflammation and oxidative stress during lower respiratory tract infections in COPD patients. Monaldi Arch Chest Dis 2003;59:273-80.

67. Van Beurden WJ, Harff GA, Dekhuijzen PN, Van Der Poel-Smet SM, Smeenk FW. Effects of inhaled corticosteroids with different lung deposition on exhaled hydrogen peroxide in stable COPD patients. Respiration 2003;70:242-8.

68. Ferreira IM, Hazari MS, Gutierrez C, Zamel N, Chapman KR. Exhaled nitric oxide and hydrogen peroxide in patients with chronic obstructive pulmonary disease: effects of inhaled beclomethasone. Am J Respir Crit Care Med 2001;164:1012-5. 69. Kostikas K, Papatheodorou G, Psathakis K, Panagou P, Loukides S. Oxidative stress in expired breath condensate of patients with COPD. Chest 2003;124:1373-80.

70. Carpagnano GE, Resta O, Foschino-Barbaro MP, Spanevello A, Stefano A, Di Gioia G, et al. Exhaled Interleukine-6 and 8-isoprostane in chronic obstructive pulmonary disease: effect of carbocysteine lysine salt monohydrate (SCMC-Lys). Eur J Pharmacol 2004;505:169-75.

71. Garcia-Rio F, Romero D, Lores V, Casitas R, Hernanz A, Galera R, et al. Dynamic hyperinflation, arterial blood oxygen, and airway oxidative stress in stable patients with COPD. Chest 2011;140:961-9.

72. Kazmierczak M, Ciebiada M, Pekala-Wojciechowska A, Pawlowski M, Nielepkowicz-Gozdzinska A, Antczak A Evaluation of Markers of Inflammation and Oxidative Stress in COPD Patients with or without Cardiovascular Comorbidities. Heart Lung Circ 2015;24:817-23.

73. Lehtimaki L, Kankaanranta H, Saarelainen S, Annila I, Aine T, Nieminen R, et al. Bronchial nitric oxide is related to symptom relief during fluticasone treatment in COPD. Eur Respir J 2010;35:72-8.

74. Ozol D, Karamanli H, Uysal S, Yigitoglu MR, Yildirim Z. Airway inflammation and tiotropium treatment in stable COPD patients. Turk J Med Sci 2014;44:804-8.

75. Liu J, Sandrini A, Thurston MC, Yates DH, Thomas PS. Nitric oxide and exhaled breath nitrite/nitrates in chronic obstructive pulmonary disease patients. Respiration 2007;74:617-23.

76. Gregus M, Foret F, Kindlova D, Pokojova E, Plutinsky $\mathrm{M}$, Doubkova M, et al. Monitoring the ionic content of exhaled breath condensate in various respiratory diseases by capillary electrophoresis with contactless conductivity detection. J Breath Res 2015;9:027107.

77. Dressel H, Muller F, Fischer R, Rommelt H, Hohlfeld JM, Behr J, et al. Independent information of nonspecific biomarkers in exhaled breath condensate. Respiration 2010;80:401-9.

78. Fritscher LG, Post M, Rodrigues MT, Silverman F, Balter $\mathrm{M}$, Chapman KR, et al. Profile of eicosanoids in breath condensate in asthma and COPD. J Breath Res 2012;6:026001.

79. Montuschi P, Kharitonov SA, Ciabattoni G, Barnes PJ. Exhaled leukotrienes and prostaglandins in COPD. Thorax 2003;58:585-8.

80. Corhay JL, Moermans C, Henket M, Nguyen Dang D, Duysinx B, Louis R. Increased of exhaled breath condensate neutrophil chemotaxis in acute exacerbation of COPD. Respir Res 2014;15:115.

81. Foschino Barbaro MP, Carpagnano GE, Spanevello A, 
Cagnazzo MG, Barnes PJ. Inflammation, oxidative stress and systemic effects in mild chronic obstructive pulmonary disease. Int J Immunopathol Pharmacol 2007;20:753-63.

82. Gessner C, Scheibe R, Wotzel M, Hammerschmidt S, Kuhn H, Engelmann L, et al. Exhaled breath condensate cytokine patterns in chronic obstructive pulmonary disease. Respir Med 2005;99:1229-40.

83. Gessner C, Rechner B, Hammerschmidt S, Kuhn H, Hoheisel G, Sack U, et al. Angiogenic markers in breath condensate identify non-small cell lung cancer. Lung Cancer 2010;68:177-84.

84. Dentener MA, Creutzberg EC, Pennings HJ, Rijkers GT, Mercken E, Wouters EF. Effect of infliximab on local and systemic inflammation in chronic obstructive pulmonary disease: a pilot study. Respiration 2008;76:275-82.

85. Ko FW, Leung TF, Wong GW, Ngai J, To KW, Ng S, et al. Measurement of tumor necrosis factor-alpha, leukotriene B4, and interleukin 8 in the exhaled breath condensate in patients with acute exacerbations of chronic obstructive pulmonary disease. Int J Chron Obstruct Pulmon Dis 2009;4:79-86.

86. Ko FW, Lau CY, Leung TF, Wong GW, Lam CW, Hui DS. Exhaled breath condensate levels of 8-isoprostane, growth related oncogene alpha and monocyte chemoattractant protein-1 in patients with chronic obstructive pulmonary disease. Respir Med 2006;100:630-8.

87. Lin XF, Zhang L, Shi SY, Fan YC, Wu ZL, Zhang X, et al. Expression of surfactant protein-A in exhaled breath condensate of patients with chronic obstructive pulmonary disease. Mol Med Rep 2016;13:1667-72.

88. Zhou F, Chen J, Tao G, Zhu M, Xie W, Cao X. Increased levels of exhaled sICAM1, sVCAM1, and sE-selectin in patients with non-small cell lung cancer. Respir Med 2014;108:1670-6.

89. Gorska K, Maskey-Warzechowska M, Nejman-Gryz P, Korczynski P, Prochorec-Sobieszek M, Krenke R. Comparative study of periostin expression in different respiratory samples in patients with asthma and chronic obstructive pulmonary disease. Pol Arch Med Wewn 2016;126:124-37.

90. Koczulla AR, Noeske S, Herr C, Koepke J, Jorres RA,
Nell C, et al. Alpha-1 antitrypsin is elevated in exhaled breath condensate and serum in exacerbated COPD patients. Respir Med 2012;106:120-6.

91. Sng JJ, Prazakova S, Thomas PS, Herbert C. MMP-8, MMP-9 and Neutrophil Elastase in Peripheral Blood and Exhaled Breath Condensate in COPD. COPD 2017;14:238-44.

92. Kwiatkowska S, Noweta K, Zieba M, Nowak D, Bialasiewicz P. Enhanced exhalation of matrix metalloproteinase- 9 and tissue inhibitor of metalloproteinase- 1 in patients with COPD exacerbation: a prospective study. Respiration 2012;84:231-41.

93. Bertini I, Luchinat C, Miniati M, Monti S, Tenori L. Phenotyping COPD by ${ }^{1} \mathrm{H}$ NMR metabolomics of exhaled breath condensate. Metabolomics 2014;10:302-11.

94. Fumagalli M, Dolcini L, Sala A, Stolk J, Fregonese L, Ferrari F, et al. Proteomic analysis of exhaled breath condensate from single patients with pulmonary emphysema associated to alpha1-antitrypsin deficiency. J Proteomics 2008;71:211-21

95. Fumagalli M, Ferrari F, Luisetti M, Stolk J, Hiemstra PS, Capuano D, et al. Profiling the proteome of exhaled breath condensate in healthy smokers and COPD patients by LCMS/MS. Int J Mol Sci 2012;13:13894-910.

96. Zakharkina T, Koczulla AR, Mardanova O, Hattesohl A, Bals R. Detection of microorganisms in exhaled breath condensate during acute exacerbations of COPD. Respirology 2011;16:932-8.

97. Carpagnano GE, Lacedonia D, Carone M, Soccio P, Cotugno G, Palmiotti GA, et al. Study of mitochondrial DNA alteration in the exhaled breath condensate of patients affected by obstructive lung diseases. J Breath Res 2016;10:026005.

98. Pinkerton M, Chinchilli V, Banta E, Craig T, August A, Bascom R, et al. Differential expression of microRNAs in exhaled breath condensates of patients with asthma, patients with chronic obstructive pulmonary disease, and healthy adults. J Allergy Clin Immunol 2013;132:217-9.

99. Vestbo J, Rennard S. Chronic obstructive pulmonary disease biomarker(s) for disease activity needed--urgently. Am J Respir Crit Care Med 2010;182:863-4.

Funding.-This publication was supported by the Janos Bolyai Research Scholarship of the Hungarian Academy of Sciences to Zsofia Lazar and Andras Bikov.

Conflict of interest.-The authors certify that there is no conflict of interest with any financial organization regarding the material discussed in the manuscript.

Manuscript accepted: March 8, 2018. - Manuscript received: February 28, 2018. 